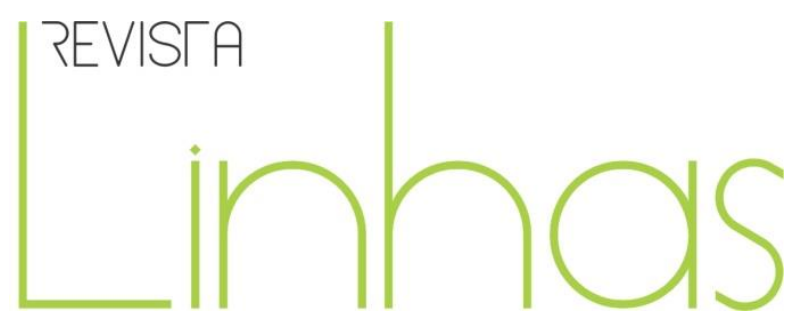

\title{
Um contexto de inclusão escolar de estudantes surdos em escola regular no sertão alagoano
}

\section{Resumo}

A educação escolar vem passando por inúmeras transformações, principalmente no que diz respeito a ofertar ensino de qualidade para todos os estudantes. Um dos maiores desafios diz respeito à inclusão escolar de alunos com surdez na escola regular, visto que estes possuem a Língua Brasileira de Sinais como meio de comunicação prioritária, elencando da escola profissionais capacitados, bem com a figura do intérprete em seu cotidiano. Assim, tem-se por objetivo analisar o ponto de vista das professoras da sala de aula comum e do Atendimento Educacional Especializado (AEE), bem como dos estudantes surdos sobre o processo de inclusão escolar no sertão alagoano. A investigação realizou-se em escola regular sob enfoque da pesquisa qualitativa com utilização de entrevista semiestruturada e observação em diário de campo. Os participantes da pesquisa foram a professora da sala de aula, a professora do AEE e os alunos surdos. Os dados foram analisados com análise de conteúdo. Como resultado, constatou-se que a escola pesquisada não estava preparada para receber os alunos com surdez, visto que não possuía intérprete de Língua Brasileira de Sinais; a professora da sala regular destes alunos não possui conhecimento sobre a surdez e suas peculiaridades, contudo a professora do AEE utilizava e ensinava a Língua Brasileira de Sinais. Consideramos, assim, que para inclusão do aluno surdo é necessário que toda a comunidade escolar se mobilize no aprendizado da Língua Brasileira de Sinais e que haja profissionais capacitados para oferecerem mais qualidade de ensino para estes alunos.

Palavras-chave: Educação Especial; Surdez; Educação.

\author{
Marily Oliveira Barbosa \\ Universidade Federal de São \\ Carlos - UFSCar - SP/Brasil \\ marilyufal@hotmail.com
}

Anderson Francisco Vitorino

Universidade Federal de Alagoas

- UFAL - AL/Brasil

andersonfran_29@hotmail.com

Andreia Bezerra Dias

Secretaria Municipal de Educação

de Pão de Açúcar - AL/Brasil

ag2.9@hotmail.com

\footnotetext{
Para citar este artigo:

BARBOSA, Marily Oliveira; VITORINO, Anderson Francisco; DIAS, Andreia Bezerra. Um contexto de inclusão escolar de estudantes surdos em escola regular no sertão alagoano. Revista Linhas. Florianópolis, v. 17, n. 35 , p. 176-192, set./dez. 2016.
} 


\title{
A context of inclusion in deaf school students in regular school alagoano sertão
}

\begin{abstract}
School education has undergone many changes, especially in regard to offer quality education for all students. One of the biggest challenges with regard to school inclusion of students with deafness in the regular school, since it has the Brazilian Sign Language as a means of communication priority, listing of qualified professional school, as well as the figure of the interpreter in their daily lives. So, one has to analyze the point of view of common classroom teachers and the Specialized Educational Service (SES) and the deaf students about the process of school inclusion in Alagoas hinterland. Research conducted in regular school under focus of qualitative research with the use of semi-structured interviews and observation in a field diary. The participants were the teacher in the classroom, the teacher of the ESA and the deaf students. Data were analyzed using content analysis. As a result, it was found that the school searched was not prepared to receive students with deafness, as it had no interpreter of Brazilian Sign Language; the teacher regular room these students do not have knowledge of deafness and its peculiarities, but SES teacher used and taught Brazilian Sign Language. We believe so for inclusion of deaf students is necessary that the entire school community mobilizes in learning Brazilian Sign Language and that have trained professionals to thus be a better teaching and learning for these students.
\end{abstract}

Keywords: Special Education; Deafness; Education. 


\section{Introdução}

A Educação no Brasil é um direito assegurado para todos os cidadãos como consta na Constituição brasileira (BRASIL, 1988). Apesar deste direito garantido, nem todas as pessoas em idade escolar estão nas escolas regulares e, quando estão, nem sempre têm a qualidade de ensino. O caso torna-se ainda mais agravante quando se trata das pessoas com deficiência, entre elas os alunos surdos, foco deste estudo. Segundo Rocha (2012, p. 10):

A pessoa surda é alguém que vivencia um déficit de audição que a impede de adquirir, de maneira natural, a língua oral/auditiva usada pela comunidade majoritária e que constrói sua identidade com base, principalmente, nesta diferença, e para isso utiliza estratégias cognitivas e de manifestações comportamentais culturais diferentes da maioria das pessoas que ouvem [...].

Diante da fala da autora, nota-se o reconhecimento dessa diferença como primeiro passo para que o surdo seja incluído na comunidade em que vive.

Muitos estudantes surdos encontram dificuldade em utilizar a Língua Brasileira de Sinais (LIBRAS) como meio de comunicação em meio ao reconhecimento oficial da sua própria língua de instrução. A falta de políticas públicas bem definidas, bem como um currículo que atenda as necessidades do aluno surdo, dificultam o acesso e permanência destes à educação de qualidade (SANTANA, 2007). Os indicadores apresentados conduzem ao empobrecimento da cultura e da comunidade surda, bem como dificultam o processo de aprendizagem no âmbito educacional dos surdos.

Segundo Strobel (2008), a história dos surdos perpassa por momentos negativos, pois, memorizam a exclusão dessas pessoas que viviam diante da sociedade que os renegavam e os convidam a vivenciar uma experiência histórica maculada de aberrações diante do contexto sociocultural.

A educação inclusiva vem se tornando uma realidade cada dia mais desafiadora, não só para os sistemas de ensino, mas também em todos os âmbitos sociais, uma vez que o direito à educação não se restringe apenas ao acesso garantido na matrícula do 
aluno, junto ao estabelecimento escolar, mas também pela participação, aprendizagem e desenvolvimento enquanto sujeitos. Dessa forma, estudos mostram questões prioritárias para desenvolvimento de práticas inclusivas na comunicação e educação de alunos surdos, focando de forma específica a LIBRAS, como instrumento essencial.

A LIBRAS é uma língua que permeia o universo da comunicação dos surdos no Brasil. É através dela que os surdos disseminam os interesses de uma cultura que perpassa por momento social, político, cultural e linguístico (ALBRES, 2013).

Uma forma de assegurar que a criança surda possa ser alfabetizada é através da Língua de Sinais. A atual legislação garante que a pessoa surda deve ter acesso aos mesmos direitos com igualdade de oportunidades no campo educacional. É direito do aluno surdo desenvolver seu aprendizado no ensino regular sem preconceito e exclusão.

A inclusão dos surdos nas escolas regulares recebeu um grande impulso após a lei de LIBRAS (lei $\mathrm{n}^{\circ}$ 10.436, de 24 de abril de 2002), ser oficializada e preconizar a LIBRAS como disciplina curricular. Vejamos o exposto no artigo $3^{\circ}$ :

Art. $3^{\circ} \mathrm{A}$ Libras deve ser inserida como disciplina curricular obrigatória nos cursos de formação de professores para o exercício do magistério, em nível médio e superior, e nos cursos de Fonoaudiologia, de instituições de ensino, públicas e privadas, do sistema federal de ensino e dos sistemas de ensino dos Estados, do Distrito Federal e dos Municípios. (BRASIL, 2002)

A Lei acima citada tem como objetivo defender de forma segura os direitos educacionais que a pessoa surda tem. Contudo, para que isso aconteça, muito ainda precisa ser feito, como entender pontos cruciais dentro desse processo, entendendo e compreendendo não só o sujeito surdo, mas as filosofias educacionais para pessoas surdas com práticas pedagógicas, auxílio de recursos humanos e um Projeto Político Pedagógico que vise um atendimento educacional qualificado às pessoas surdas.

Entende-se que a LIBRAS é conhecida como meio legal de comunicação e expressão. Inclusive o Ministério da Educação (MEC) aponta que a educação dos surdos deve ser bilíngue, assegurando o direito de acesso à Libras e à língua portuguesa escrita, ensinadas no contraturno, com a participação de educadores surdos e professores 
bilíngues. Nota-se que a pessoa que fala duas línguas é considerada bilíngue, sendo que a Língua de Sinais é conhecida como primeira língua (L1) e a Língua Portuguesa, como segunda língua (L2) para pessoas surdas (BRASIL, 2002).

Considera-se como outra conquista para a comunidade surda, a regulamentação da Lei $n^{\circ}$ 12.394/10, que reconhece a profissão de tradutor e intérprete da Língua Brasileira de Sinais (Libras) - Língua Portuguesa, que intermedia em vários contextos, inclusive, educacional. Conforme apresenta a Lei $n^{\circ}$ 10.436/2002:

Art. 21. A partir de um ano da publicação deste Decreto, as instituições federais de ensino da educação básica e da educação superior devem incluir, em seus quadros, em todos os níveis, etapas e modalidades, o tradutor e intérprete de Libras - Língua Portuguesa, para viabilizar o acesso à comunicação, à informação e à educação de alunos surdos. $\S 1^{\circ}$ O profissional a que se refere o caput atuará: Nos processos seletivos para cursos na instituição de ensino; Nas salas de aula para viabilizar o acesso dos alunos aos conhecimentos e conteúdos curriculares, em todas as atividades didático-pedagógicas; No apoio à acessibilidade aos serviços e às atividades-fim da instituição de ensino. (BRASIL, 2002)

Diante do exposto, percebe-se que o profissional tradutor e intérprete de Libras Língua Portuguesa, é responsável por viabilizar o acesso à comunicação, informação e à educação de alunos surdos nas salas de aula, possibilitando o ensino de conteúdos curriculares em todas as atividades, e contando com o apoio da instituição de ensino, que garante a acessibilidade dos alunos. Com isso, observa-se a importância e a necessidade dessas leis para o reconhecimento dos surdos como comunidades linguísticas e sociais, principalmente como profissional, uma vez que a lei diz que a pessoa surda tem prioridade no ensino de Libras.

Nota-se que no decreto $n^{\circ} 5.626$ de 2005 há uma preocupação com os surdos no contexto educacional, sobretudo, no tocante linguístico com a proposta de incluir os surdos nas escolas e sala de aulas, de forma que esta inclusão passe por todo contexto escolar - gestão, pessoal administrativo e professor -, e que, diariamente, seja respeitada a LIBRAS como forma de expressão dos surdos (BRASIL, 2005). 
O Atendimento Educacional Especializado para pessoas com surdez tem como objetivo estabelecer a compreensão e o reconhecimento do potencial e das capacidades individuais, no processo de ensino-aprendizagem o qual será de ajuda também para o seu desenvolvimento pleno, incluindo o ensino e aperfeiçoamento da LIBRAS.

Nessa mesma direção, a Política Nacional de Educação Especial na Perspectiva da Educação Inclusiva (2008) define que o Atendimento Educacional Especializado “[...] identifica, elabora e organiza recursos pedagógicos e de acessibilidade, que eliminem as barreiras para plena participação dos alunos, considerando suas necessidades especificas" (BRASIL, 2008, p. 17).

De acordo com os dispositivos legais, todas as pessoas com deficiência, possivelmente, devem ser incluídas em instituições de ensino regular, sobretudo, na Educação Básica e ainda, serem encaminhadas em turno contrário para o atendimento a ser realizado no AEE. Entende-se que o AEE tem a função de proporcionar aos alunos público-alvo da educação especial, inclusive os surdos, subsídios pedagógicos e/ou acessíveis com a perspectiva de incluí-los considerando suas potencialidades e peculiaridades específicas.

O AEE articulado ao ensino e à prática da LIBRAS serve de base nos conteúdos curriculares desenvolvidos em sala de aula, sendo que esse tipo de atendimento para o aluno surdo contribui na participação e compreensão sobre o que está sendo tratado pelo professor para, assim, poder interagir com seus colegas (ALVEZ, FERREIRA; DAMÁZIO, 2010).

Diante deste aspecto, temos por objetivo analisar o ponto de vista das professoras da sala de aula comum e do AEE, bem como dos estudantes surdos sobre o processo de inclusão escolar no sertão alagoano. 


\section{Metodologia}

Para a realização de tal pesquisa, adotamos a pesquisa de caráter qualitativo. Segundo Flick (2009), os métodos qualitativos consideram a comunicação do pesquisador com o campo e seus membros como parte explícita da produção do conhecimento, caracterizando-se pela interação direta entre o pesquisador e o objeto de estudo. Neste tipo de pesquisa, existe a explicitação sobre a teoria, escolha de tópicos da pesquisa, método e interpretação dos resultados.

Para obtermos os dados da pesquisa, utilizamos a entrevista semiestruturada. $O$ objetivo deste tipo de entrevista "é revelar o conhecimento existente de tal modo que se possa expressá-lo na forma de respostas, tornando-se assim, acessível à interpretação" (FLICK, 2009, p. 153). A entrevista semiestruturada é definida como um processo de entrevista que consiste em perguntas escolhidas de antemão com o objetivo de extrair informações dos entrevistados podendo, quando necessário, acrescentar novas perguntas, visando resultados importantes para a pesquisa em questão (ANGROSINO, 2009).

A escolha pela escola pesquisada como campus de estudo, deu-se por ser uma escola localizada no sertão alagoano que atende aos moradores da cidade, do campo e principalmente os filhos dos trabalhadores rurais, e entre eles havia dois alunos surdos. A pesquisa foi realizada numa escola Municipal, tendo a participação de uma professora que atuava no AEE e uma professora da sala de aula comum. Ambas estavam envolvidas com dois alunos surdos, Pedro e Maria. Ambos frequentavam o $9^{\circ}$ (nono ano) do Ensino Fundamental, sendo que Pedro tinha 21 (vinte e um) e Maria, 19 (dezenove) anos de idade.

Em relação à professora do $\mathrm{AEE}$, esta possuía Graduação em Pedagogia e Especialização em Atendimento Educacional Especializado - AEE; tinha 42 (quarenta e dois anos) e atuava em duas escolas do município.

Já a professora da sala de aula comum era graduada em Pedagogia, possuía curso de magistério e curso de Libras. Ela tinha 32 (trinta e dois anos) de idade. Visando atender aos padrões de ética relacionados à pesquisa, atribuímos a todos os participantes da 
pesquisa nomes fictícios. Assim, as professoras passarão a ser chamadas: Ana (professora da sala de recursos multifuncionais) e Paula (professora da sala de aula comum).

As entrevistas foram realizadas individualmente e, em relação aos alunos com surdez, elas foram feitas com a colaboração da professora do AEE na turma na qual os alunos surdos estavam inseridos. É importante ressaltar que as professoras realizaram a entrevista mesmo não sendo um ato obrigatório. As entrevistas foram gravadas na íntegra e posteriormente transcritas.

Para a coleta de dados, inicialmente foram realizadas as entrevistas com as professoras Ana e Paula, nas quais foram explicados os objetivos da pesquisa, e ainda esclarecidas algumas dúvidas. Logo após, foram feitas observações sobre a prática das duas docentes em seus ambientes de atuação. Para o registro dessas observações, foram utilizadas anotações em diário de campo.

Em seguida, foram feitas as entrevistas de natureza semiestruturadas, realizadas individualmente, iniciadas pela professora Ana e, posteriormente, pela professora Paula. Sempre focando as expectativas em relação ao aluno surdo, as potencialidades, as dificuldades relacionadas à docência, as estratégias que vinham utilizando, os conteúdos que estavam sendo trabalhados, enfim, tudo que fosse considerado necessário pelos docentes. Em um momento posterior, foram realizadas as entrevistas com os dois alunos surdos na sala de recursos multifuncional por intermédio da professora do AEE.

Posteriormente às entrevistas e transcrições, foi realizada uma leitura juntamente com uma análise minuciosa e exaustiva de todos os dados, e, a partir deles, foram levantadas as categorias. Neste processo fez-se uso da análise de conteúdo. Minayo (2004, p. 209) menciona que este tipo de análise “[...] consiste em descobrir os núcleos de sentido que compõem uma comunicação cuja presença ou frequência signifiquem alguma coisa para o objeto analítico visado", e desdobra-se em três etapas: pré-análise; exploração do material e tratamento dos resultados obtidos, e interpretação. Através da direção da análise de conteúdo, foram criadas as categorias que serão discutidas a seguir. 


\section{Resultados e análise dos dados}

\section{1 - A escola e sua relação com a educação especial: a sala de recursos multifuncionais em foco}

A partir dos dados da pesquisa, observamos que a escola tem uma íntima relação com a educação especial, inclusive foi exposto pelas professoras que a escola possui o projeto político pedagógico e que nele consta a educação especial. Diante da fala das professoras Ana e Paula, subtende-se que a escola trabalha com a proposta da inclusão das pessoas com deficiência e nela encontram-se matriculados alunos com surdez, autismo, deficiência intelectual e deficiência visual.

A partir do exposto, observamos que as professoras trabalham com diversos alunos com deficiência, inclusive com alunos surdos, foco da nossa pesquisa. $\mathrm{O}$ decreto $\mathrm{n}^{\circ}$ 7.611 (2011) traz um extenso público-alvo da educação especial e cabe aos professores aprender a lecionar para cada um deles. Estes são os alunos com deficiência, transtornos globais do desenvolvimento e altas habilidades/superdotação (BRASIL, 2011).

Ao perguntar se escola trabalha com a atual proposta da Política Nacional de Educação Especial na Perspectiva da Educação Inclusiva, tendo por foco o AEE e qual a forma que as professoras atuam nesse sentido, elas explicitaram que:

Sim, [a escola trabalha com a proposta de AEE] atendendo os educandos no contraturno, onde na sala de recursos existem três profissionais especializados e os educandos são atendidos por deficiência. Além destes profissionais, os educandos são atendidos por professores de educação física, oficinas de reciclagem e artesanato, informática e braile. (professora Ana)

Sim, [a escola trabalha com a proposta de AEE] atende de acordo com cada necessidade do aluno. (professora Paula)

Diante do exposto, analisa-se como a escola atende a esses alunos de acordo com suas especificidades, buscando atendê-los dentro do AEE. Para Lacerda (2006, p. 167):

A inclusão escolar é vista como um processo dinâmico e gradual, que pode tomar formas diversas a depender das necessidades dos alunos, já 
que se pressupõe que essa integração/inclusão possibilite, por exemplo, a construção de processos linguísticos adequados, de aprendizado de conteúdos acadêmicos e de uso social de leitura e da escrita, sendo o professor responsável por mediar e incentivar a construção do conhecimento através da interação com ele e com os colegas.

A escola possui o AEE, que muitas vezes acontece na sala de recursos multifuncionais, utilizando inclusive os recursos didáticos pedagógicos que existem nela para trabalhar com os alunos público-alvo da educação especial. Vejamos o que as professoras relatam:

Sim, possui sala de recursos multifuncionais e utilizamos jogos diversos, material dourado, trabalho com material construído de acordo com a proposta do professor que está na sala de aula regular. Ele dá a informação para gente, e daí se constrói aquele material de acordo com o conteúdo que vai ser trabalhado, nem sempre todos dão, mas aqueles que dão, agente constrói material [recursos didáticos pedagógicos]. Mas a escola tem muito material que é comprado, que vem do MEC, a escola compra com o PDDE e o MEC disponibiliza de acordo com as deficiências que tem na escola, tipo dominó em LIBRAS, jogos em braile e outros materiais. (Professora Ana)

Sim, [possui SRM] material dourado, dominós em LIBRAS, dominós das operações, alfabeto ilustrado e de alfabetização, dominós e formas geométricas em braile, memória tátil, caixinha de números em braile, dominós silábicos, livros de histórias, pranchas de comunicação, quebracabeça (diversos), fantoches de personagens (Chapeuzinho Vermelho e outros). (Professora Paula)

De acordo com as professoras, percebe-se que é necessário que a escola disponibilize materiais didáticos lúdicos pedagógicos a fim de atender uma demanda que complemente a aprendizagem dos alunos público-alvo da educação especial. Segundo Lacerda (2006), as dificuldades enfrentadas para inclusão de alunos com deficiência no âmbito educacional estão relacionadas à sociedade que deve se adaptar dando suporte para que possamos contribuir para a formação de uma nova escola, onde se possa atender a todos. 


\section{2 - A surdez e a LIBRAS: o movimento da inclusão do aluno surdo?}

Com relação à surdez e à LIBRAS na escola pesquisada, observamos que ambas são presentes no cotidiano escolar, principalmente pela participação ativa de dois estudantes surdos regularmente matriculados. Ambos os alunos fazem uso da LIBRAS e frequentam o AEE no contraturno, duas vezes por semana. Alguns atendimentos são realizados individualmente e outros na dupla de alunos surdos. A fim de compreendermos como as professoras compreendem a surdez, perguntamos a elas o que seria o surdo. Vejamos a seguir suas falas:

[Surdez] para mim é a perda da audição, que pode ser leve, moderada ou profunda. (professora Ana)

[surdez] para mim é o indivíduo que por algum motivo não ouve [escuta] nada. (professora Paula)

A partir das concepções das professoras, a surdez está ligada à perda auditiva. Esse discurso vai ao encontro do Decreto $n^{\circ} 5.626 / 2005$ que traz:

Considera-se pessoa surda aquela que, por ter perda auditiva, compreende e interage com o mundo por meio de experiências visuais, manifestando sua cultura principalmente pelo uso da Língua Brasileira de Sinais - LIBRAS. (BRASIL, 2005)

Relacionado ao aluno surdo, perguntamos se a escola disponibiliza um intérprete de LIBRAS. Relataram o seguinte:

Não [existe intérprete]. As escolas aqui do município, em nenhuma existe o intérprete de LIBRAS. (professora Ana)

Não [existe intérprete]. É uma pena, pois me ajudaria muito em sala de aula. (professora Paula) 
Diante das falas das professoras, percebe-se o quanto é necessária a presença de um intérprete de LIBRAS nas escolas regulares e principalmente em sala de aula. Inclusive consta na Lei $\mathrm{n}^{\circ}$ 10.436/2002 que é direito do aluno surdo a presença de um intérprete de LIBRAS (BRASIL, 2002), contudo muitas escolas não cumprem o estabelecido em Lei.

Ainda sobre o cotidiano do aluno surdo, perguntamos se a escola em que as professoras trabalhavam estava preparada para receber alunos surdos. Vejamos a seguir o que as professoras dizem:

[se a escola está preparada] Preparados nunca estamos, posso dizer que existe profissional com formação específica para atendê-los no AEE, porém muito ainda precisa ser feito para que estes sejam atendidos adequadamente, a exemplo de: intérprete na sala de aula e formação para todo o corpo docente. (professora Ana)

[se a escola está preparada] Não, na minha opinião, apesar da escola já trabalhar com inclusão, bem como haver algumas ações que já acontece na escola. Acredito que falta um planejamento pedagógico que atenda essa demanda. (professora Paula)

A partir das concepções das professoras, percebe-se que apesar da escola já receber alunos público-alvo da educação especial há algum tempo, nota-se que há necessidade de diversas modificações. Assim, a escola vai se preparando, se adequando de acordo com as necessidades que vão surgindo.

Relacionado ao aluno surdo, perguntamos o seguinte: como as docentes se sentem trabalhando com alunos surdos. Vejamos o que responderam:

Me sinto muito feliz em poder estar contribuindo na vida pessoal, educacional e social, procurando atender de forma significativa para a construção de saberes. (professora Ana)

Eu, apesar de não saber LIBRAS, eu tento me comunicar com eles através da escrita na Língua Portuguesa, e ainda tento falar com os alunos de forma que eles entendam através da leitura labial. Sinto-me útil, mas vejo a necessidade de aprender LIBRAS, porque quando eles não me entendem, ou vice-e-versa, o que eu estou ensinando, eu necessito chamar sempre a professora da Sala de Recurso Multifuncional. (professora Paula) 
Realizando ainda uma análise através das falas das professoras e das observações em diário de campo, percebemos que a professora da sala de recursos multifuncionais que trabalha com surdos, apesar de não ter uma formação específica de LIBRAS como, por exemplo, a formação em Letras/LIBRAS, que a habilite para ensinar os surdos, possui cursos básico de LIBRAS e especialização em AEE, e atende os alunos surdos no horário contrário realizando um agendamento individual. Quanto à professora da sala de aula regular, percebemos que não há um planejamento de aula para atender as necessidades dos alunos surdos; dá-se aula como se todos os alunos fossem ouvintes, e ainda, utiliza instrumentos pedagógicos não visuais, bem como não sabe se comunicar com os alunos surdos em LIBRAS, submetendo a comunicação através do professor de AEE. Além disso, a professora não tem formação específica e não busca se capacitar para atender o público surdo.

O fato da professora da sala de aula não saber LIBRAS e de não haver um intérprete dificulta o acesso ao conhecimento para estes estudantes. Embora a professora Paula afirme se comunicar pela escrita ao invés da LIBRAS, visualizamos o quão árduo é o processo educacional do ensino/aprendizagem do aluno surdo. Há necessidade de formação para os docentes e que esta seja organizada pelo poder público, visto que não há como culpabilizar a professora por não saber LIBRAS, nem como inocentá-la por isso. De fato, o cotidiano dos professores é complexo no que diz respeito à carga horária para formação continuada, contudo não há como falar em inclusão de alunos surdos se não houver a LIBRAS presente no processo de ensino para estes alunos (ALBRES, 2013).

Diante dos aspectos da não utilização das LIBRAS na sala de aula, buscamos desvelar a opinião das professoras sobre a proposta de inclusão trabalhada na escola, tentando saber se os alunos surdos conseguem aprender os conteúdos transmitidos pelos professores de sala de aula, bem como, na SRM. Eis, a seguir, os relatos:

Na sala de recursos percebe-se um avanço significativo no tocante da aprendizagem de leitura na modalidade escrita. No que diz respeito à sala de aula, ainda está em processo, paulatinamente. (professora Ana) 
Acredito que na Sala de Recurso Multifuncional a professora deve trabalhar com os alunos surdos bem melhor do que os professores de sala de aula regular. Percebo que apesar dos professores de sala de aula regular e sala de recurso participarem de encontros pedagógicos na escola, as ações e planejamentos de aula não são postos em prática em sala de aula. Alguns professores dizem que não dispõem de tempo para planejar aulas específicas. (professora Paula)

A partir das concepções das professoras, analisa-se o quanto deve haver um planejamento que atenda a necessidade de aprendizado dos alunos e utilização da LIBRAS. Os alunos surdos entrevistados expuseram a importância da LIBRAS, ao expor que:

[...] é muito bom saber que alguém me entende. (aluna Maria)

Me sinto muito feliz em saber que tem alguém que se comunica comigo através da LIBRAS. (aluno Pedro)

Diante das falas dos alunos verifica-se a importância da Língua de Sinais no processo de comunicação para com os surdos. Inclusive os alunos surdos afirmam que tentam passar para os outros a LIBRAS, inclusive para seus familiares. Vejamos o que dizem:

[se ensina LIBRAS aos familiares] Sim, muitas vezes ensinei para meu pai e minha mãe, mas eles são fracos para aprender LIBRAS, só conseguia falar pequenas palavras em LIBRAS como: mãe e pai. (aluna Maria)

[se ensina LIBRAS aos familiares] Sim, minha mãe e meu pai sabem algumas palavras em LIBRAS, mas meus irmãos sabem um pouquinho, pelo menos umas palavrinhas. (aluno Pedro)

Percebe-se o quanto a comunicação dos alunos surdos depende da Língua de Sinais como principal veículo, e o quanto é importante que professores e familiares aprendam o uso dessa língua para que assim dialoguem entre si (BARBOSA, MELO JUNIOR; SANTOS, 2011). As pessoas surdas necessitam interagir com seus professores e familiares e a forma que melhor beneficia este diálogo é por intermédio da LIBRAS. 


\section{Considerações finais}

Consideramos que as escolas pesquisadas que trabalham com a proposta de inclusão de alunos com deficiência, em questão, os alunos surdos, não utilizam a língua de sinais como sua primeira língua (L1), e ainda, não há intérpretes de LIBRAS que possa intermediar e interpretar as interações orais entre professor e aluno em sala de aula regular. Sabe-se que apesar dos alunos surdos estarem acobertados pela lei que oficializa a LIBRAS (10.436 de 22 de abril de 2002), os seus direitos legais não são respeitados, podendo assim, comprometer o seu processo de ensino/aprendizagem.

Diante dos fatos pesquisados, percebemos que nas escolas que trabalham com inclusão de alunos surdos muito ainda precisa ser feito, pois, diante do estudo, observamos que há necessidade de profissionais qualificados e/ou capacitados com metodologias e estratégias que possam atender aos alunos surdos adequadamente, já que a inclusão não é somente matricular alunos surdos nas escolas comuns, incluir é buscar estratégias que possam atender a todos e que essas estratégias metodológicas façam sentido para aqueles que têm deficiência.

Nesta pesquisa pudemos considerar, em relação ao aluno surdo, o quanto é necessária a utilização da LIBRAS, pois é fundamental para que haja compreensão e interação com o mundo. Pudemos perceber isso a partir do momento em que o aluno está na sala de aula sem o uso da língua de sinais e sem intérprete de LIBRAS, ficando impossibilitado de interagir com qualidade junto a todas as pessoas (professores, colegas de turma, etc.). Com a utilização da LIBRAS, o aluno surdo consegue compreender diversos assuntos trabalhados na escola, no meio social e familiar.

Entende-se que incluir não só é colocar o aluno com surdez na sala regular e acreditar que ele está incluso; para que a inclusão realmente aconteça é necessário que cada profissional se disponha a buscar estratégias metodológicas que venham a atender a todos.

Diante do exposto, sugerimos que os profissionais que atendem os alunos com surdez devem inovar, a favor de uma escola para todos e de uma educação que possibilite a construção de uma nova cultura e valorização das diferenças. 
Esperamos, assim, que este trabalho motive outros pesquisadores para novas buscas, fomentando novos conhecimentos científicos que possibilitem mudanças reais em todo o processo educacional.

\section{Referências}

ALBRES, Neiva de Aquino. Comunicação em LIBRAS: para além dos sinais. In: LACERDA, Cristina Broglia Feitosa de; SANTOS, Lara Ferreira dos (Org). Tenho um aluno surdo, e agora? Introdução à LIBRAS e educação de surdos. São Carlos: Edufscar, 2013.

ALVEZ, Carla Barbosa, FERREIRA, Josimário de Paula; DAMÁZIO, Mirlene Macedo. A educação especial na perspectiva da inclusão escolar: abordagem bilíngue na escolarização de pessoas com surdez. Brasília: Ministério da Educação, Secretaria de Educação Especial, 2010.

ANGROSINO, Michael. Etnografia e observação participante. Porto Alegre: ARTMED, 2009.

BARBOSA, Marily Oliveira, MELO JUNIOR, Arlindo Lins de; SANTOS, Arlete Rodrigues O bullying e a violência na escola: concepções de um professor surdo. In: ENCONTRO DE PESQUISA EM EDUCAÇÃO DE ALAGOAS (EPEAL), VI, Maceió-AL, 2011. Anais... Maceió: Edufal, 2011.

BRASIL. Constituição da República Federativa do Brasil. Brasília: Imprensa Oficial, 1988.

BRASIL. Ministério da Educação. Lei de Diretrizes e Bases da Educação Nacional, LDB 9.394, de 20 de dezembro de 1996. Brasil: MEC, 1996.

BRASIL. Lei $\mathbf{n}^{\circ}$ 10.436, de 24 de abril de 2002. Dispõe sobre a Língua Brasileira de Sinais LIBRAS e dá outras providências. Brasília: MEC/SEESP, 2002.

BRASIL. Decreto $n^{\circ}$ 5.296, de 2 de dezembro de 2004. Regulamento as Leis $n^{\circ} 10.048,8$ de novembro de 2000. Brasília, MEC/SEESP, 2004.

BRASIL. Decreto ${ }^{\circ} \mathbf{5 . 6 2 6}$ de 22 de Dezembro de 2005, que dispõe sobre a Língua Brasileira de Sinais-LIBRAS. Brasília, MEC/SEESP, 2005.

BRASIL. Política Nacional de Educação Especial na Perspectiva da educação Inclusiva. Brasília, MEC/SEESP, 2008.

BRASIL. Decreto $\mathbf{n}^{\circ}$ 7.611, de 17 de novembro de 2011. Dispõe sobre a educação especial, o atendimento educacional especializado e dá outras providências. 2011.

FLICK, Uwe. Introdução à pesquisa qualitativa. 3. ed. Porto Alegre: Artmed , 2009. 
LACERDA, Cristina Broglia Feitosa de. A inclusão escolar de alunos surdos: O que dizem alunos, professores e intérpretes sobre estas experiências. Cad. Cedes, Campinas, v. 26, n. 69, p.163-184, maio/ago.2006.

MINAYO, Maria Cecília de Souza. O desafio do conhecimento: pesquisa qualitativa em saúde. 8. ed. São Paulo: Hucitec-Abrasco, 2004.

ROCHA, Andreia de Lima Campos. Elaboração de material didático: Uma necessidade na educação de surdos. Brasília 2012.

SANTANA, Ana Paula. Surdez e linguagem: aspectos e implicações neurolinguísticas. São Paulo: Plexus, 2007.

STROBEL, Karin. História da Educação de Surdos. Florianópolis: Ed. da UFSC, 2008.

Universidade do Estado de Santa Catarina - UDESC

Programa de Pós-Graduação em Educação - PPGE

Revista Linhas

Volume 17 - Número 35 - Ano 2016

revistalinhas@gmail.com 